\title{
Current Status and Countermeasures on English Writing Teaching for Colleges and Universities
}

\author{
Haiyan Sun \\ College of Foreign Languages, Bohai University, Jinzhou, 121013, China \\ sunhaiyan0@163.com
}

Keywords: colleges and universities; English writing teaching; current status and countermeasures

\begin{abstract}
Writing is an important means of students' language output, training students' English writing ability, and fully reflects the comprehensive language using ability. Writing teaching has always been the weak link of English teaching, the cultivation of colleges and universities English writing requirements and teaching methods, on the basis of the analysis of the status quo of college English writing teaching, find out the existing problems and put forward corresponding countermeasures, for deepen the reform of English teaching and improve the quality of English teaching services. Specific strategies include: break the students' English writing vocabulary obstacles, to ensure that students sufficient comprehensible language input, deepen the reform of the teaching of English writing from various angles, to construct a system of corpus for use in writing teaching.
\end{abstract}

\section{Introduction}

English writing course is a compulsory course for English majors of colleges and universities, and also one of the compulsory courses of training students' communication ability. The level of English writing is the embodiment of the English comprehensive ability. English writing teaching, from the English word, sentence, paragraph and analysis and the characteristics of the article, let the students understand and master English writing words, sentence structure and the characteristics of the paragraphs, chapters; Students through reading and play their own writing practice, systematically master the basic knowledge and basic skills in English writing, adept at writing all sorts of English practical writing, improve writing ability, strive to achieve accurate words, grammatically correct, the habit of expression in English; Through the teaching to students lay a solid basic skills of writing English, lay a foundation for training foreign language talents. Writing teaching has always been the weak link of English teaching, the analysis of the status quo of college English writing teaching, find out the existing problems and put forward corresponding countermeasures, for deepening the reform of English teaching and improving the quality of English teaching services.

\section{Training Requirements on English Writing Teaching for Colleges and Universities}

Teaching of English writing course is divided into in basic expression and writing stage, the training requirements are:

(1) Basic expression phase of basic requirements including three aspects: first, vocabulary, mastering 8000-10000 words and their usage, skilled correctly use of around 2000 commonly used words and phrases formed by these words. Second, language, master various grammatical structure and sentence cohesion between methods, right way to write the patterns and use a variety of cohesion coherent express ideas. Three is, writing ability, according to the prompt or in 30 minutes to write a 120-150 words essay, do relevant content, clear and grammatically correct; Able to rewrite or abbreviated text content; Correctly written note and inform practical writing, etc.

(2) The basic requirement of writing stage including four aspects: one is that vocabulary, in mastering and able to skillfully use common vocabulary, on the basis of learn to use some new words and phrases. The second is, the language, can correct use of all kinds of sentence patterns and common figures of speech to write sentences, make the language expression image and vivid. The third is the thought. The article to the center needs novel and depth, to resonate with readers. Four is, 
writing ability, can according to the topic and requirements given articles written genres in 45 minutes, the article length of 300-400 or so words; Be distinct themes, rich content, language fluency, decent and word and expression, be able to use some figures of speech; Can write the length of 5000-10000 or so words of graduation thesis, requires clarity, substantial in content, language fluency.

\section{Methods on English Writing Teaching for Colleges and Universities}

The present typical English writing teaching some method [1-3] consists of the following:

(1) The process teaching methods. Writing focus on the writing process, students in the process of writing in a timely manner for teachers' help, feedback and guidance, in to motivate the students and develop students' thinking ability and so on has a good effect. It is mainly divided into four stages: first, the preparation before writing. Students according to the writing subject for the topic and conception, the teacher help the students to open their ideas. Second, draft stage, the student will draw up a written design result, teachers' individual guidance. Third, the change stage, the students find and solve problems, students under the guidance of teachers. Fourth, finalized stage, students according to their teachers' views on the article written up. Four stages can be linear, also can be a return, and cross throughout the writing process.

(2) The result teaching methods. Emphasis on external conditions and language environment on the leading role in the development of human language, teachers in a dominant position, the students repeat to enhance learning by imitation and focus on the final result. Usually put the writing is divided into four areas: the first, familiar with model essay, the teacher to choose a model essay and explain, to analyze its rhetoric and language characteristics. Second, the control practice, teacher fan in this paper, we observed the sentence asked the students to practice with gradually transition to the paragraph writing. Third, guiding practice, students imitate model essay, using the trained sentence try to write a similar type of articles. Fourth, free writing, students freely play, making the writing skills become part of their skills, and used in practical writing.

(3) The hierarchical teaching method. According to different level students' personality traits, learning abilities, interests and hobbies, adopt different teaching methods, is the embodiment of principle of their aptitude. Layered teaching is to face all, and to take care of the individual, play to the students at all levels of expertise, improve the learning ability. English writing teaching layered target is roughly: C level students can apply simple vocabulary and grammar structure describes the main content, strive to finishing writing task; Student B layer can be accurately applied vocabulary and grammatical structure, application of simple statement connections between components, rules of writing task; Students can apply A layer of high grammatical structures and vocabulary, try to use more complicated structure and higher word, effectively use statements connections between components, fully achieve the desired purpose.

\section{Current Status on English Writing Teaching for Colleges and Universities}

Current situation of college English writing teaching is not optimistic, satisfaction of students in English writing teaching is low and the interest is not high, lack of a high level of English writing teachers, foreign teachers writing teaching level is not high. Through in-depth investigation and analysis, summed up the main problems of the [4-6] as follows:

(1) The students' English basic skill is not solid. Language basic skills are fundamental to show the features of English major students and advantages, English level also reflected the basic skills are solid. English writing, we should use the correct, appropriate, appropriate language and means to accurately express ideas. Common sense mistakes you often make when writing, including a mixture of tense and voice, vocabulary, prepositions conjunction misuse, wrong sentences messy problem such as incomplete. A more important issue is to master vocabulary is too little, the sentence pattern lacks less accumulation of phrase, phrases and phrases. Writing level is still keep at a lower level, shallow short written articles. 
(2) The students' English language ability is poor. English course goal is to cultivate students' comprehensive language using ability. Comprehensive language using ability is to use the language communication task. Comprehensive application based on language knowledge, language skills, emotional attitudes, learning strategies and cultural awareness, etc. Grammar chaos is students the most direct and the most major problem. Students' language ability difference is mainly manifested in poor ability to basic grammar and discourse structure. Besides grammatical errors, is more serious is that statement logic is not strict, and even chaos. And chapter structure, expression meaning is not clear, the argument is not sufficient, depth is not enough.

(3) The expression way of thinking. Way of thinking is a method that people to think about the problem. Thinking determines the diversity of language expression from different angles. The thinking mode affects the expression of ideological content and linguistic form. China's Confucian culture dominated by intuition thinking, on the whole grasp things; Western philosophy thinking take subject and object opposites as the starting point, rely on the abstract rational expression. The obvious difference is that, in the daily communication, Chinese people like to say first reason and purpose, and westerners like to say first intention and reason. Many students of English writing is always lack of "taste", the reason is that there is no way according to western habit to write. Teachers lack the cultivation of student's thinking mode, so that the students don't know their own problems in writing.

(4) The English writing teaching mode is old. Writing is to find the most effective language to communicate thoughts and feelings of the continuous process, is the cycle complex psychological cognition, creation and social interaction process of thinking. The traditional teaching mode lack of guidance to the student, not enough information to students input, no creative platform structures, cognitive and thinking. Writing process is simply material translation process, the lack of interaction between teachers and students, the lack of information and the exchange of ideas, the lack of idea of dialogue and collision, lack of creative thinking and knowledge internalization and build process, could not be opened the thinking ways of students, writing interest are banned, writing motivation and creativity are suppressed.

\section{Countermeasures on English Writing Teaching for Colleges and Universities}

Aiming at the existing problems of college English writing teaching, and puts forward countermeasures as follows [7-10]:

(1) Break through the students' English writing vocabulary obstacles. Vocabulary is the foundation of language, to master a certain vocabulary is to improve the English "listening, speaking, reading, writing and translation", etc. Various abilities necessary guarantee. English vocabulary learning is very extensive, including the definition of "word, word form and composition, the meaning of the word, the meaning of the relationship between the word and the word, the relationship between word meaning and context, the constitution of the idiom, and use, the types of dictionary and use, vocabulary, the relationship between vocabulary and culture, the history of word frequency statistics" and so on many aspects. On the degree of familiar with and master the vocabulary and writing are closely related. Teachers should adjust the vocabulary teaching strategies, teach students scientific and effective memory method, train the students' ability to proper use of vocabulary; Make full use of modern information technology to deepen the student to the word memory; Education psychology thought, systematic and ordinary knowledge easier to understand and memory. When teachers explain the new words to help students connect in the mind learned words, and comparative analysis; Want to maintain long-term memory, review consolidate from time to time and students to form the good habit of consciously review vocabulary. Really master words need a lot of practice, teachers should provide lexical reiteration chances for students, and guide the students in the concrete application of master vocabulary, encourage them every opportunity to enrich vocabulary.

(2) Ensure that students sufficient comprehensible language input. Language input refers to the language learners hear and read the material. Trough processing these materials, forming in the mind the target language rules system. Comprehensible input is the result of language input in the 
form of simplified. Not only strengthen the grasp basic English knowledge but also language skills, and helps students to actively build a genre, such as cultural background knowledge schema. RodEllis made the following eight kinds of language input: "A high quantity of input directed at the learner, The learner's perceived need to communicate, Independent control of the propositional content by the learner, Adherence to the 'here and now principle', The learner needs the opportunity to listen to and to produce language used to perform different language functions, Exposure to a high quantity of directives, Exposure to a high quantity of 'extending utterances', Opportunities for uninhibited 'practice"'. English writing teaching includes not only the lexical, syntactic language knowledge such as written exercises, and pay attention to the cohesion between sentences and paragraphs of text structure, and according to the different writing object using a different genre, and consideration of cultural differences of Chinese and western social cultural standards make students writing in English. Students of the existing experience and knowledge is the basis of constructing new knowledge structure, have sufficient knowledge of the language input, will form a new structure, to form effective language output.

(3) We will deepen reform of the teaching of English writing from all directions. Mainly from three aspects: one is that writing teaching content choice, living style and theme, the combination of writing content must conform to the actual needs of the readers. Arrangement before writing task to combine the students' actual level and interest, in real life, discuss the writing subject, make writing actualized, the writing as a process of communicative activities, implement "writing topic into life, and life into the writing topic" situation. Second, writing teaching method on orientation, presupposition and generation in hand. Due to differences in individual understanding and the teaching resources of uneven distribution factors, such as writing teaching should be based on respect for reality, scene preset and practice writing class to generate the situation of coexistence. Teachers according to their own teaching ideas, style and experience, build a "bottom-up" to adapt to the concrete writing teaching scenario, based on the classroom teaching of writing teaching theory system. Three is that writing teaching evaluation, the diversified evaluation methods is a trend. Different students have different understanding and grasp of the knowledge of writing level. Diversified evaluation is the real trend of effective teaching. Implementation "self assessment", "mutual" and "teacher evaluation of" the combination of a variety of ways, such as appraisal way, both inside and outside the classroom to realize real feedback of student writing learning, for the teaching schedule coordination play a guiding role.

(4) Build a suit corpus for use in writing teaching system. Corpus for language appeared real language materials in practical use. Teachers can create composition corpus, also can establish model essay corpus, a collection of works of English. Through corpus assist complete the writing part: one is that before writing, teachers of writing, the students in the retrieval model essay corpus under the guidance of teachers, the proposition thesis discuss key words, sentence structures and language features of information, through model corpus retrieval, observation in the language and the use of continuous inspection and correction hypothesis, using the rich corpus to discover and explore learning resources; Second, in writing, by keywords retrieval and contextual co-occurrence find using the characteristics of words or phrases, the wrong type of statistical data feedback to students, real-time monitoring of the error in the process of writing. Students from a large amount of language corpus, in an instance, the characteristics was summarized and classified according to the context, find out the regular characteristic; The third it is, after the writing, by corpus, retrieval and statistics provide a series of parameters for teachers to grade, reduce the workload of teachers correcting, to avoid the error correcting a composition with the subjective judgment. In the field of writing teaching, corpora provide students with rich context, is advantageous to the construction of students' language knowledge and autonomous learning ability.

\section{Conclusion}

"Outline of colleges and universities English teaching for English majors" pointed out that [11], the purpose of English writing course is to cultivate students English writing ability, including the outline, articles, essays, and the simple practical writing. Course setting time according to the actual 
situation of universities, teaching content arrangement, from the perspective of the words and sentence structure, asked the students, according to the prompt composition or imitate model essay writing, or according to the certain situation of string, and then transiting to paragraph writing skills, text layout and essay writing. In this paper, the research results, to seriously implement the "syllabus" required to provide a train of thought, to improve the level of English writing teaching provides the solution, plays an important role in students' language comprehensive ability raise.

\section{Acknowledgment}

This work is supported by Social Science Foundation of Liaoning Province (L15BYY008): Research on two-way culture teaching in English writing teaching for colleges and universities.

\section{References}

[1] Z. Dai, "The construction of college English blended learning model in the teaching of hierarchical classification," Journal of Chongqing University of Science and Technology (Social Sciences Edition), vol. 22, no. 11, pp. 38-41, 2015.

[2] X. Y. Wang, "The Interaction between English Writing Teaching Methods and Writing Ability," Journal of Lanzhou Petrochemical College of Vocational Technology, vol. 15, no. 1, pp. 66-70, 2015.

[3] Baidu library, "English composition teaching method," http://wenku.baidu.com/link?url=UbIt8TTrbZWcqKApZXsC4dKFAo90u9IBr6uiEFhodKAcv9 6QyeqtU4-ectOURiT1uKQINDBM43f73C5CjHZlegO_h2_pFYHVH5jzJ5Vs45a, 2016-5-1.

[4] A. M. Chen, "Investigation and Research on the present situation of college English writing teaching," Journal of Lanzhou Institute of Education, vol. 31, no. 7, pp. 125-127, 2015.

[5] X. M. Chen, J. Liu, "English major students writing present situation investigation and strategy research," Overseas English, vol. 15, no. 23, pp. 124-125, 2014.

[6] J. Chen, "Research on the thinking pattern and the differences of expression way between Chinese and English," Journal of Hubei Radio \& Television University, vol. 29, no. 7, pp. 101-102, 2009.

[7] Y. J. Hu, "Importance and methods of college English vocabulary teaching," Journal of Educational Institute of Jilin Province, vol. 3, no. 7, pp. 105-106, 2010.

[8] W. T. Li, "Theoretical relationship on two language acquisition and language input," New West, vol. 11, no. 11, pp. 123-124, 2010.

[9] L. Li, "Exploration of writing teaching mode based on self built small corpus," Journal of Yangtze Normal University, vol. 27, no. 3, pp. 46-49, 2011.

[10] S. G. Li, X. D. Zhu, "Problems and Countermeasures of College English Writing Teaching," Journal of Jilin TV \& Radio University, vol. 28, no. 4, pp. 153-155, 2015.

[11] Baidu library, "English Teaching Syllabus for English Majors in Colleges and Universities," http://wenku.baidu.com/link?url=_u8yHO1rLnh8TpiShtyyngWrOrMR9XLTfZqNpV-EfC4QE VyyzdoK41vnXVMADyAy-KMma2eLtfA9_RWaK79C6_5K3LfoY6mhQzWvpC3v2He, 2016-5-1. 